\title{
Proses Pelapisan Nikel Diatas Al Dengan Metode Elektroplating
}

\author{
Cahaya Rosyidan ${ }^{(a) *}$, Mustamina Maulani $^{(b)}$, Lisa Samura ${ }^{(\mathrm{c})}$, dan Onnie \\ Ridaliani $^{(\mathrm{d})}$ \\ Prodi Teknik Perminyakan, Jakarta, Indonesia, 11440 \\ Email: ${ }^{\left(a^{*}\right)}$ cahayarosyidan@trisakti.ac.id, ${ }^{\left({ }^{b}\right)}$ mustamina@trisakti.ac.id, ${ }^{\left({ }^{c}\right)}$ lisa.samura@trisakti.ac.id, \\ dan $^{(d)}$ onnie@trisakti.ac.id,
}

Diterima (28 Juli 2021), Direvisi (30 Juli 2021)

\begin{abstract}
Metal coatings are starting to be widely used as a way to prevent metals from corroding. In addition to preventing corrosion, metal coatings have been developed to thicken metals, increase hardness, wear resistance, and corrosion resistance. Characterization of the materials used using SEM, and XRD. The SEM characterization results show a crystal shape similar to a pyramid. The increasing coating time will increase the crystal size with the preferred plane orientation direction is [111] with the largest crystal size in the experiment with a time of $4.5 \mathrm{~h}$ which is $55.44 \mathrm{~nm}$ using the Williamson-Hall method.
\end{abstract}

Keywords: Electroplating, SEM, XRD.

\begin{abstract}
Abstrak. Pelapisan logam mulai banyak digunakan sebagai cara untuk mencegah logam dari korosi. Selain mecegah korosi, pelapisan logam mulai dikembangkan untuk mempertebal logam, meningkatkan kekerasan, ketahanan aus, dan ketahanan korosi.. Karakterisasi material yang digunakan dengan menggunakan SEM,dan XRD. Pada hasil karakterisasi SEM mempelihatkan bentuk kristal yang mirip dengan piramida. Semakin meningkatnya waktu pelapisan akan menaikan ukuran kristal dengan arah orientasi bidang yang disukai adalah [111] dengan ukuran kristal terbesar pada percobaan dengan waktu $4.5 \mathrm{j}$ yaitu sebesar $55,44 \mathrm{~nm}$ yang menggunakan metode Williamson-Hall.
\end{abstract}

Kata kunci: Pelapisan, SEM, XRD.

\section{PENDAHULUAN}

Logam aluminium menjadi salah satu material yang banyak digunakan masyarakat seperti transportasi, bangunan dan konstruksi serta aksesoris dan dekorasi rumah karena sifatnya lunak dan penampilan bergaya, warnanya keperakan dan mengkilap. Harga cukup terjangkau serta mudah didapatkan, berbeda pemanfaatan logam aluminium pada bidang keteknikan, pada bidang keteknikan penggunaan logam aluminium karena logam aluminium mudah dibentuk, sebuah konduktor panas yang baik, tahan terhadap suhu dingin, aluminium juga dapat terkorosi. [1][2]
Pelapisan logam mulai banyak digunakan sebagai cara untuk mencegah logam dari korosi. Selain mecegah korosi, pelapisan logam mulai dikembangkan untuk mempertebal logam, meningkatkan kekerasan, ketahanan aus, dan ketahanan korosi [3][4]. Banyak faktor yang mempengaruhi untuk mendapatakan hasil keuntungan tersebut diantaranya adalah komposisi bahan, komposisi larutan [5][6], suhu larutan [7][8][9], kuat arus larutan[10]-[12], durasi pencelupan dan tegangan listrik larutan[5], [10]-[17]. Proses electroplating telah lama dikenal untuk pelapisan logam seperti nikel, krom, emas, dan perak. Metode elektroplating menawarkan banyak kelebihan seperti 
lebih cepat, terpercaya dan biayanya relatif lebih murah [18][19][20]-[23].

Ukuran kristal memiliki impresi langsung pada energi permukaan lapisan. Seiring dengan energi permukaan, morfologi permukaan juga memainkan peran penting dalam keterbasahan permukaan. Karena dari perubahan $\mathbf{M}$ kerapatan arus (j) dapat diperoleh ketebalan, morfologi lapisan dan ukuran kristal. Oleh karena itu dalam riset ini akan dicari perubahan mikrostruktur lapisan dan sebaran partikel $\mathrm{Ni}$ di atas substrat Al dengan variasi waktu [24], [25].

Penelitian yang dilakukan oleh Zubar yo dkk menggunakan larutan elektrolit $\mathrm{NiSO} 4.6 \mathrm{H}_{2} \mathrm{O}\left(210 \mathrm{~g} \mathrm{~L}^{-1}\right), \mathrm{NiCl}_{2.6} \mathrm{H}_{2} \mathrm{O}(20$ $\left.\mathrm{gL}^{-1}\right)$ dan $\mathrm{H}_{3} \mathrm{BO}_{3}\left(45 \mathrm{~g} \mathrm{~L}^{-1}\right)$ [26]. Larutan ini disebut juga sebagai larutan watts karena menggunakan tiga komponen pendukung utama seperti Nikel sulfat, nikel klorida dan boric acid

Meskipun penelitian mengenai pelapisan Nikel di atas substrat alumnium telah banyak dilakukan. Meskipun penelitian pelapisan Nikel ke aluminium dengan variasi waktu telah banyak dilakukan, namun masih banyak yang kurang menjealaskan dengan detail mengenai pengaruh pelapisan nikel diatas aluminium dengan metode elektrodeposit terhadap ukuran kristal, morfologi permukaan. Karakterisasi material pada penelitian ini menggunakan SEM, dan XRD.

\section{PENELITIAN}

\section{Bahan dan Persiapan}

Batang anoda yang digunakan adalah logam nikel murni 98\% dan anodanya adalah substrat aluminium. Larutan elektrolit yang digunakan adalah larutan watts $\mathrm{NiSO} 4.6 \mathrm{H}_{2} \mathrm{O} \quad\left(210 \mathrm{~g} \quad \mathrm{~L}^{-1}\right)$, $\mathrm{NiCl}_{2.6} \mathrm{H}_{2} \mathrm{O}\left(20 \mathrm{gL}^{-1}\right)$ dan $\mathrm{H}_{3} \mathrm{BO}_{3}\left(45 \mathrm{~g} \mathrm{~L}^{-}\right.$ $\left.{ }^{1}\right)$ dengan kualitas/grade analis dari pabrik kimia Merck. Sebelum dilakukan percobaan logam aluminium diamplas dan dicuci dalam larutan ultrasonik.

\section{Morfologi dan Struktur}

Gambar 1 memperlihatkan evolusi mikrostruktur pelapisan Nikel murni diatas Aluminium dengan variasi waktu. Terlihat dari hasil SEM Nikel tersebar merata di atas substrate Aluminium pada proses elektroplating dengan waktu $3.5 \mathrm{j}$ (Gambar 1a). Kemudian secara visual terlihat dari penambahan waktu menjadi $4.5 \mathrm{j}$ ukuran kristal semakin membesar dan terlihat cukup dekat satu sama lain (Gambar 1b). Pada variasi waktu $5 \mathrm{j} \mathrm{h}$ secara visual ukuran kristal menjadi lebih kompak dan terikat satu sama lain (Gambar 1c).

Tabel 1: Komposisi kimia dari nikel murni yang diuji dari XRF

\begin{tabular}{lc}
\hline Unsur & Konsentrasi ( \% ) \\
\hline $\mathrm{Al}$ ( Alumunium ) & 0,02 \\
$\mathrm{Ca}$ ( Kalsium ) & 0,04 \\
$\mathrm{Fe}$ ( Besi ) & 0,23 \\
$\mathrm{Ni}$ ( Nikel ) & $\mathbf{9 8 , 0 1}$ \\
$\mathrm{Y}$ ( Yitrium ) & 1,61 \\
$\mathrm{Zr}$ ( Zirkon ) & 0,04 \\
$\mathrm{Nb}$ ( Niobium ) & 0,05 \\
\hline
\end{tabular}




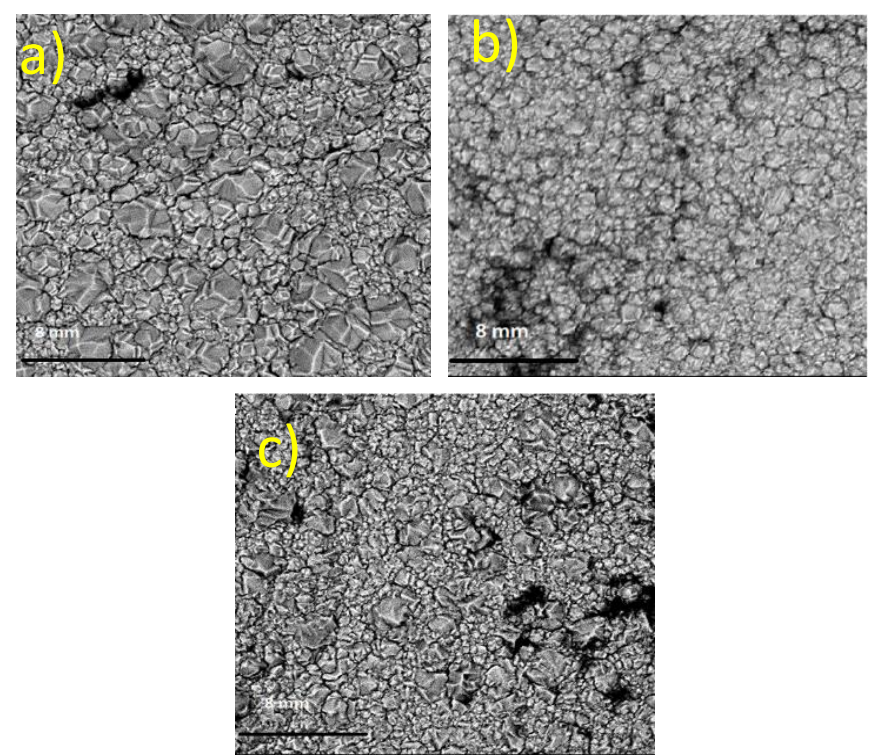

Gambar 1.(a-c) hasil morfologi SEM dengan perbesaran 10.000 x untuk variasi waktu

Tabel 2: Parameter hasil karakterisasi XRD

\begin{tabular}{|c|c|c|c|}
\hline \multirow{2}{*}{ Parameter } & \multicolumn{3}{|c|}{ Sampel } \\
\hline & 3.5 jam & 4.5 jam & 5 jam \\
\hline $\begin{array}{c}\text { Struktur } \\
\text { Kristal }\end{array}$ & Cubic FCC & Cubic FCC & $\begin{array}{l}\text { Cubic } \\
\text { FCC }\end{array}$ \\
\hline $\begin{array}{l}\text { Space } \\
\text { Group }\end{array}$ & Fm-3m & Fm-3m & Fm-3m \\
\hline $\begin{array}{l}\text { space } \\
\text { Group } \\
\text { Number }\end{array}$ & 225 & 225 & 225 \\
\hline $\begin{array}{c}\text { Parameter } \\
\text { Kisi }(\AA) \\
\mathrm{a}=\mathrm{b}=\mathrm{c}\end{array}$ & 3,5175 & 3,5206 & 3,5152 \\
\hline $\begin{array}{c}\text { Volume } \\
\left(\AA_{3}\right)\end{array}$ & 44.36 & 44.36 & 44.36 \\
\hline $\begin{array}{l}\text { Densitas } \\
(\mathrm{g} / \mathrm{cm} 3)\end{array}$ & 8,79 & 8,79 & 8,79 \\
\hline $\begin{array}{c}d \text {-spacing } \\
(\AA)\end{array}$ & 1,0142 & 1,0093 & 1,0137 \\
\hline $\begin{array}{c}\text { Crystallite } \\
\text { Size } \\
\text { Williamson- } \\
\text { Hall } \\
\text { (nm) }\end{array}$ & 20,69 & 55,44 & 21,00 \\
\hline $\begin{array}{c}\text { GOF } \\
\text { (Goodness } \\
\text { of Fit) }\end{array}$ & 0,8837 & 2,04934 & 0,98324 \\
\hline
\end{tabular}

ola XRD yang dihasilkan Pola XRD yang ditampilan pada Gambar 2 adalah hasil rietveld refinement dari pola XRD yang diolah menggunakan software HighscorePlus Software. Struktur kristal yang dibentuk adalah face centered cubic (FCC) yang menunjukan tiga puncak signifikan untuk bidang [111], [002] dan [022]. Fasa yang terbentuk adalah fasa tunggal dan tidak ada fasa lainnya yang terbentuk di permukaan lapisan $\mathrm{Ni}$.

Terdapat tiga intensitas puncak yang berbeda secara signifikan, puncak-puncak tersebut adalah bidang [111], [002] dan [022]. Perbedaan intensitas puncak ini disebabkan oleh perbedaan rapat massa di permukaan setiap bidang kristal akibat variasi waktu.

Selain itu, parameter yang tak kalah pentingnya yaitu ukuran butir (crystallite size) dengan metode Williamson-Hall. Metode Williamson-Hall memiliki dua faktor yaitu $\beta_{L}$ dan $\beta_{e}$ sehingga dapat dilakukan plot dengan membentuk persamaan akhir menjadi serupa dengan persamaan garis lurus, yaitu $y=m x+c$. Persamaan yang digunakan dalam plot disebut sebagai W-H plot, dan diberikan pada Persamaan 1 berikut ini [27].

$$
\beta \operatorname{Cos} \theta=C \varepsilon \operatorname{Sin} \theta+\frac{K \lambda}{L}
$$



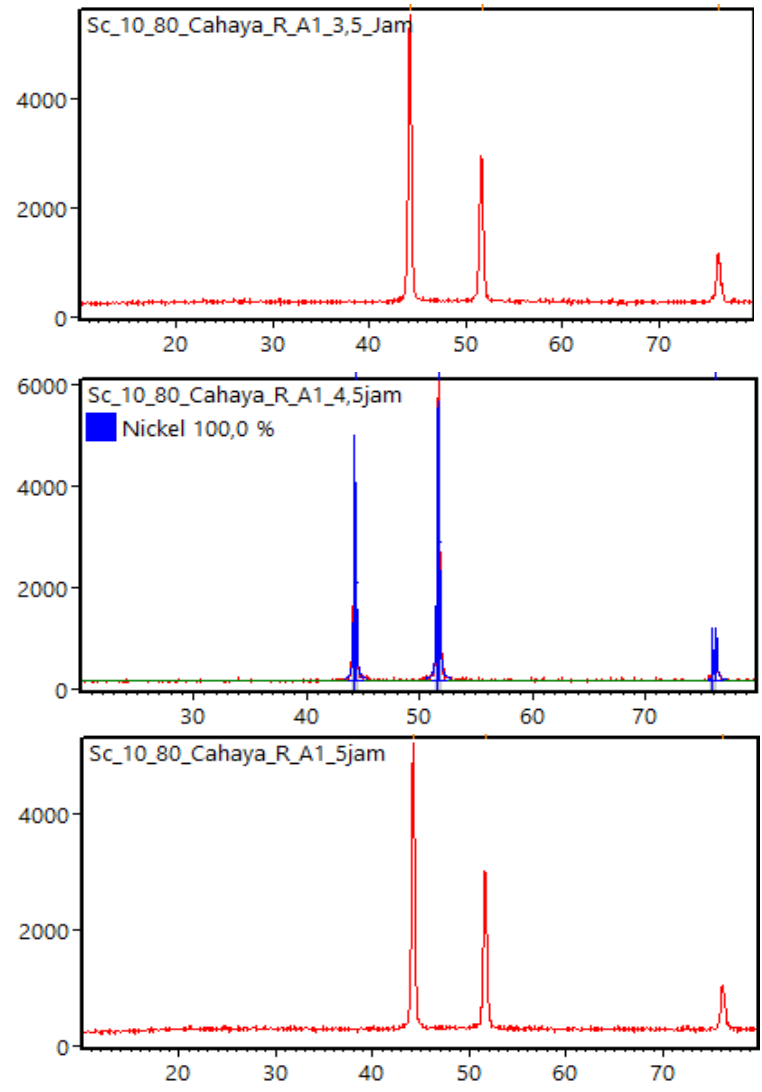

Gambar 2. Pola XRD dari pelapisan Nikel ke Al dengan variasi waktu pada arus $50 \mathrm{~mA}$

Hasil karakterisasi XRD ditampilkan pada Tabel 2. Dengan menggunakan perangkat lunak Highscore Plus. Nilai parameter kisi menunjukkan fenomena naik dan turun seiirng dengan perubahan waktu. Hal ini berkaitan dengan berkurangnya nilai $d$-spacing dimana diakibatkan oleh adanya residual stress yang memberikan kompresi terhadap mikrostruktur material itu sendiri sebagai bentuk respons material terhadap perubahan waktu.
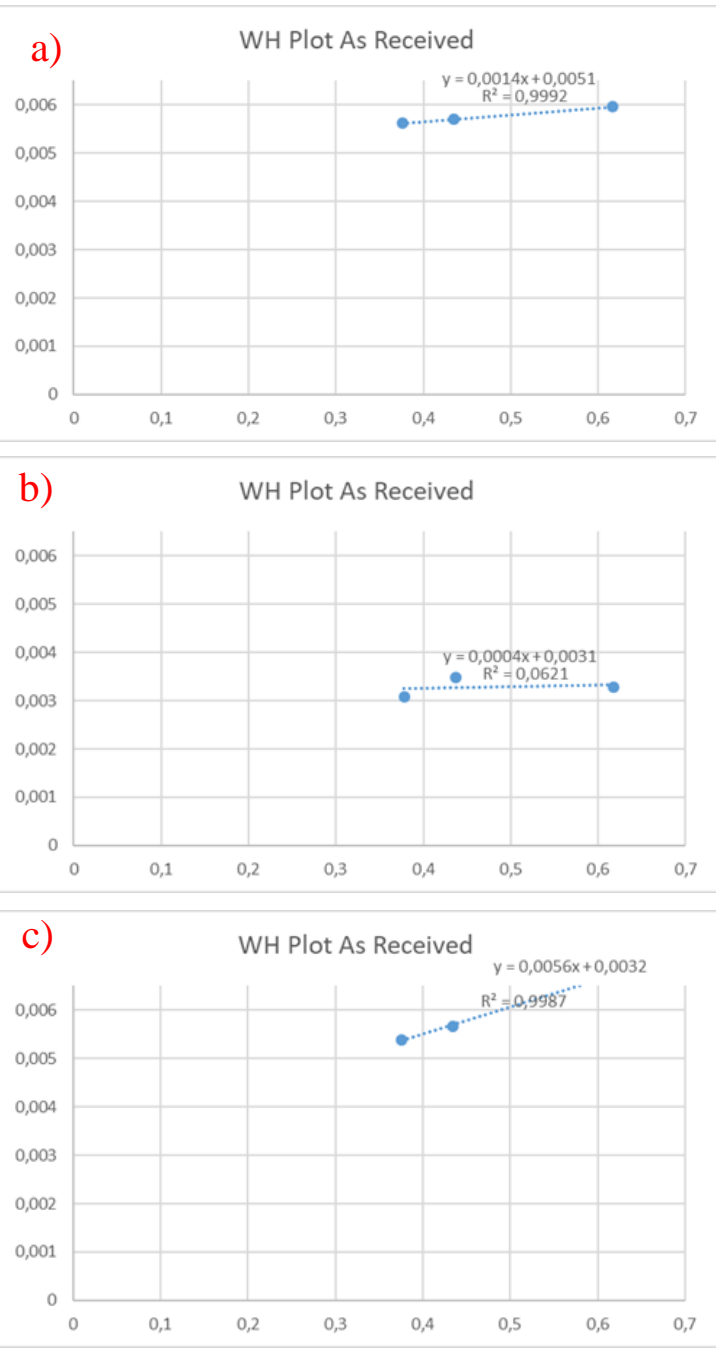

Gambar 3. W-H Plot pada pelapisan Ni ke Al dengan variasi waktu a) 3.5 jam, b) 4.5 jam dan c) 5 jam

\section{KESIMPULAN}

Telah berhasil dilakukan pelapisan Nikel diatas substrate Al dengan variasi waktu. Efek pelapisan Ni mempengaruhi morfologi permukaan, dan ukuran krsital. Variasi waktu $4.5 \mathrm{j}$ mempunyai ukuran kristal paling besar dengan metode Williamson-Hall sebesar $55,44 \mathrm{~nm}$ dengan bidang kristal yang paling dominan [111]. Struktur morfologi kristal berbentuk piramida dengan sebaran kristalnya terdistribusi menyeluruh di atas substrate $\mathrm{Al}$. 


\section{UCAPAN TERIMAKASIH}

Ucapan terima kasih kepada Fakultas Teknologi Kebumian dan Energi yang telah mensupport dan membiayai penelitian ini dari dana hibah internal Universitas Trisakti.

\section{DAFTAR PUSTAKA}

[1] J. Sudagar, J. Lian, and W. Sha, "Electroless nickel, alloy, composite and nano coatings - A critical review," J. Alloys Compd., vol. 571, pp. 183-204, 2013.

[2] A. V. Logunov, D. V. Danilov, and R. V. Khramin, "High-Strength Nickel-Based Alloy SLGS-5 for Operation in Active Marine Salt Corrosion Environment," Mater. Today Proc., vol. 11, pp. 453-458, 2019.

[3] N. Li, W. Li, X. Yang, Y. Xu, and A. Vairis, "Corrosion characteristics and wear performance of cold sprayed coatings of reinforced $\mathrm{Al}$ deposited onto friction stir welded AA2024-T3 joints," Surf. Coatings Technol., vol. 349, no. April, pp. 1069-1076, 2018.

[4] F. Soleimangoli, S. A. Hosseini, A. Davoodi, A. Mokhtari, and M. Alishahi, "Effect of $\mathrm{NH} 4 \mathrm{Cl}$ on the microstructure, wettability and corrosion behavior of electrodeposited $\mathrm{Ni}-\mathrm{Zn}$ coatings with hierarchical nano/microstructure," Surf. Coatings Technol., vol. 394, no. April, p. 125825, 2020.

\section{B. ABEDINI, N. PARVINI}

AHMADI, S. YAZDANI, and L. MAGAGNIN, "Electrodeposition and corrosion behavior of $\mathrm{Zn}-\mathrm{Ni}-\mathrm{Mn}$ alloy coatings deposited from alkaline solution," Trans.
Nonferrous Met. Soc. China (English Ed., vol. 30, no. 2, pp. 548-558, 2020 .

[6] K. S. Jyotheender, A. Gupta, and C. Srivastava, "Grain boundary engineering in $\mathrm{Ni}$-carbon nanotube composite coatings and its effect on the corrosion behaviour of the coatings," Materialia, vol. 9, no. October 2019, p. 100617, 2020.

[7] K. Mausam and M. Goyal, "Development of nanocrystalline NiAl coatings and its thermal stability," Mater. Today Proc., no. xxxx, 2020.

[8] F. B. Susetyo, M. C. Fajrah, and B. Soegijono, "Effect of electrolyte temperature on properties of nickel film coated onto copper alloy fabricated by electroplating," $e$ Journal Surf. Sci. Nanotechnol., vol. 18, no. 10, pp. 223-230, 2020.

[9] L. Jinlong, L. Tongxiang, and W. Chen, "Effect of electrodeposition temperature on grain orientation and corrosion resistance of nanocrystalline pure nickel," J. Solid State Chem., vol. 240, pp. 109-114, 2016.

[10] B. Li et al., "Effect of current density and deposition time on microstructure and corrosion resistance of $\mathrm{Ni}-\mathrm{W} / \mathrm{TiN}$ nanocomposite coating," Ceram. Int., vol. 45, no. 4, pp. 4870-4879, 2019.

[11] H. S. Maharana, B. Bishoyi, and A. Basu, "Current density dependent microstructure and texture evolution and related effects on properties of electrodeposited Ni-Al coating," $J$. Alloys Compd., vol. 787, pp. 483494, 2019.

[12] Sutomo, Senen, and Rahmat, 
"Pengaruh arus dan waktu pada pelapisan nikel dengan elektroplating untuk bentuk plat," Fak. Tek. Univ.

Diponegoro, Indones.

[13] S. Raharjo, "Pengaruh Variasi Tegangan Listrik Dan Waktu Proses Electroplating Terhadap Sifat Mekanis Dan Struktur Mikro Baja Karbon Rendah Dengan Krom Samsudi," Jurnal.Unimus.Ac.Id, pp. 296-308, 2010.

[14] A. M. Koten, J. U. Jasron, J. T. Mesin, U. N. Cendana, and K. Mikro, "Pengaruh Variasi Tegangan dan Waktu Terhadap Kekerasan Lapisan Nikel dengan Metode Electroplating pada Coran Aluminium scrap," vol. 03, no. 01, 2016.

[15] A. F. Alphanoda, "Pengaruh Jarak Anoda-Katoda dan Durasi Pelapisan Terhadap Laju Korosi pada Hasil Electroplating Hard Chrome," J. Teknol. Rekayasa, vol. 1, no. 1, p. 1, 2017.

[16] D. Suwardi, "Pengaruh Elektroplating Nikel Dengan Variasi Waktu Pelapisan 30, 60, 90, 120, 150 Menit Terhadap Kekasaran Permukaan, Titik Luluh Kekuatan Tarik Maksimum Baja Karbon," J. Tek. mesin Fak. Tek. Univ. MUHAMMADIYAH SURAKARTA, 2017.

[17] M. Y. Niam, H. Purwanto, and S. M. B. Respati, "Pengaruh Waktu Pelapisan Elektro ...," vol. 13, no. 1, pp. 7-10, 2017.

[18] F. Nasirpouri et al., "An investigation on the effect of surface morphology and crystalline texture on corrosion behavior, structural and magnetic properties of electrodeposited nanocrystalline nickel films," Appl. Surf. Sci., 2014.

[19] M. Abdulwahab, O. S. I. Fayomi, and A. P. I. Popoola, "Structural evolution, thermomechanical recrystallization and electrochemical corrosion properties of $\mathrm{Ni}-\mathrm{Cu}-\mathrm{Mg}$ amorphous coating on mild steel fabricated by dual-anode electrolytic processing," Appl. Surf. Sci., 2016.

[20] M. M. Kamel, Z. M. Anwer, I. T. Abdel-Salam, and I. S. Ibrahim, "Nickel electrodeposition from novel lactate bath," in Transactions of the Institute of Metal Finishing, 2010.

[21] M. A. M. Ibrahim and R. M. Al Radadi, "Role of glycine as a complexing agent in nickel electrodeposition from acidic sulphate bath," Int. J. Electrochem. Sci., 2015.

[22] C. qun LI, X. hai LI, Z. xin WANG, and $\mathrm{H}$. jun GUO, "Nickel electrodeposition from novel citrate bath," Trans. Nonferrous Met. Soc. China (English Ed., 2007.

[23] Z. Shafiee, M. E. Bahrololoom, and B. Hashemi, "Electrodeposition of nanocrystalline $\mathrm{Ni} / \mathrm{Ni}-\mathrm{Al} 2 \mathrm{O} 3$ nanocomposite modulated multilayer coatings," Mater. Des., 2016.

[24] M. H. M. Zaki, Y. Mohd, and N. N. C. Isa, "The effect of current density on surface properties of electrodeposited copper coatings on modified aluminium," in AIP Conference Proceedings, 2018.

[25] A. Augustin, K. U. Bhat, K. R. Udupa, and A. C. Hegde, "Electron microscopic study of nodules formed 
during electrodeposition of copper on aluminium," in Materials Science Forum, 2015.

[26] T. Zubar et al., "The effect of heat treatment on the microstructure and mechanical properties of $2 \mathrm{~d}$ nanostructured au/nife system," Nanomaterials, vol. 10, no. 6, pp. 114, 2020.

[27] D. Nath, F. Singh, and R. Das, "Xray diffraction analysis by Williamson-Hall, Halder-Wagner and size-strain plot methods of $\mathrm{CdSe}$ nanoparticles- a comparative study," Mater. Chem. Phys., vol. 239, no. April 2019, p. 122021, 2020. 
Cahaya Rosyidan : Proses Pelapisan Nikel Diatas Al Dengan Metode Elektroplating 